\title{
PERCEÇÕES DE LIDERANÇAS SOBRE A ATUAÇÃO DAS AUTARQUIAS LOCAIS NO DESENVOLVIMENTO DO DESPORTO EM PORTUGAL
}

\section{Resumo}

Jorge Emanuel Oliveira Machado Mestre

FADEUP - Universidade do Porto. Porto, Portugal. jmachado_adv@hotmail.com

José Pedro Sarmento Doutor

FADEUP - Universidade do Porto Porto, Portugal. psarmento@fade.up.pt

iD Carlos Alberto Figueiredo da Silva

Doutor

PPGCAF - Universidade Salgado de Oliveira

Rio de Janeiro / RJ. Brasil.

ca.figueiredo@yahoo.com

Objetivo do estudo: Descrever as principais perceções de dirigentes associativos, políticos e empresários sobre a atuação das autarquias locais e dos demais agentes desportivos com quem se relacionam sobre o desenvolvimento do desporto em Portugal.

Metodologia/abordagem: Utilizou-se uma abordagem qualitativa, com base na herança da etnometodologia, cujos instrumentos de recolha foram: a observação participante, o focus group e entrevistas semiestruturadas.

Originalidade/Relevância: Constatou-se que o papel das autarquias no desenvolvimento do desporto em Portugal é substancial. Entretanto, quando se busca a relação destas com o setor produtivo e com as universidades, verifica-se uma grande lacuna.

Principais resultados: Os achados vão no sentido de reconhecer a importância e necessidade de planear estrategicamente, observando a relação necessária e fundamental que as autarquias devem assumir com o setor produtivo, o Estado e as universidades.

Contribuições teóricas/metodológicas: O modelo teórico da hélice tríplice ancora, neste estudo, as reflexões sobre o papel das autarquias e suas relações com diferentes atores da rede. A utilização do conceito-chave de indicialidade traz uma abordagem pouco utilizada em estudos desta natureza.

Contribuições sociais/para a gestão: Os clusters de desenvolvimento incluem a participação fundamental das universidades no pleito criativo e de inovação. Elas são fontes geradoras de ideias, ações, produtos, tecnologias que fazem movimentar o processo cumulativo e em espiral do conhecimento. Realçar o protagonismo das universidades contribui para o aprimoramento da gestão e da perceção da sociedade sobre esta área do conhecimento.

Palavras-chave: Gestão. Hélice tríplice. Desporto. Autarquias locais. Sustentabilidade. 
Machado, J. E. O., Sarmento, J. P., \& Silva, C. A. F. da. (set./dez. 2020). Perceções de lideranças sobre a atuação das autarquias locais no desenvolvimento do desporto em Portugal

\section{$\underline{\text { Cite como }}$}

American Psychological Association (APA)

Machado, J. E. O., Sarmento, J. P., \& Silva, C. A. F. da. (set./dez. 2020). Perceções de lideranças sobre a atuação das autarquias locais no desenvolvimento do desporto em Portugal. PODIUM Sport, Leisure and Tourism Review, São Paulo, 9(3), 539-567. https://doi.org/10.5585/podium.v9i3.17894.

\section{LEADERSHIP PERCEPTIONS ON THE PERFORMANCE OF LOCAL AUTHORITIES IN THE DEVELOPMENT OF SPORT IN PORTUGAL}

Purpose: Describe the primary perceptions of associative leaders, politicians, and entrepreneurs about the performance of local authorities and other sports agents with whom they relate to the development of sport in Portugal.

Methodology/approach: A qualitative approach was used, based on the heritage of ethnomethodology, whose collection instruments were: participant observation, focus group, and semi-structured interviews.

Originality/Relevance: It was found that municipalities' role in the development of sport in Portugal is substantial. However, when looking for their relationship with the productive sector and universities, there is a big gap.

Main results: The findings aim to recognize the importance and need to strategically plan, observing the necessary and fundamental relationship that municipalities must assume with the productive sector, the State, and universities.

Theoretical/methodological contributions: In this study, the triple helix model contributes to the reflections on autarchies' role and their relations with different network actors. The use of the critical concept of indexicality brings an approach little used in studies of this nature.

Development clusters include universities' fundamental participation in the creative and innovation process. They are sources that generate ideas, actions, products, technologies that move the cumulative and spiraling process of knowledge. Emphasizing universities' role contributes to improving management and society's perception of this area of expertise.

Keywords: Management. Triple helix. Sport. Local authorities. Sustainability.

\section{PERCEPCIONES DE LIDERAZGO SOBRE EL DESEMPEÑO DE LAS AUTORIDADES LOCALES EN EL DESARROLLO DEL DEPORTE EN PORTUGAL}

\section{Resumen}

El objetivo del estudio: describir las percepciones primarias de los líderes asociativos, políticos y empresarios sobre el desempeño de las autoridades locales y otros agentes deportivos con quienes se relacionan con el desarrollo del deporte en Portugal.

Metodología/enfoque: se utilizó un enfoque cualitativo, basado en la herencia de la etnometodología, cuyos instrumentos de recolección fueron: observación participante, grupo focal y entrevistas semiestructuradas. 
Originalidad/Relevancia: se descubrió que el papel de los municipios en el desarrollo del deporte en Portugal es sustancial. Sin embargo, cuando se busca su relación con el sector productivo y las universidades, existe una gran brecha.

Resultados principales: Los resultados apuntan a reconocer la importancia y la necesidad de planificar estratégicamente, observando la relación necesaria y fundamental que los municipios deben asumir con el sector productivo, el Estado y las universidades.

Contribuciones teóricas/metodológicas: en este estudio, el modelo teórico de los anclajes de triple hélice refleja el papel de las autarquías y sus relaciones con los diferentes actores de la red. El uso del concepto crítico de indexicalidad trae un enfoque poco utilizado en estudios de esta naturaleza.

Contribuciones sociales/de gestión: los grupos de desarrollo incluyen la participación fundamental de las universidades en el proceso creativo y de innovación. Son fuentes que generan ideas, acciones, productos, tecnologías que mueven el proceso acumulativo y en espiral del conocimiento. Hacer hincapié en el papel de las universidades contribuye a mejorar la gestión y la percepción de la sociedad de esta área del conocimiento.

Palabras clave: Gestión. Tripla hélice. Deporte. Autoridades locales. Sostenibilidad.

\section{Introdução}

O desporto goza de uma omnipresença e de uma omnipotência, invulgares nos dias de hoje, quando comparado com outras realidades. Como refere Amador (2003, p. 81), "o Desporto pauta a vida quotidiana do planeta, enquanto fenómeno quase omnipresente, para os que o praticam (e são bastantes), para os que a ele assistem (e são muitos) e para os que dele falam (e são quase todos)"(Bento \& Constantino, 2012).

Tratando-se o desporto de matéria de interesse público e estando consagrado na Constituição da República Portuguesa, a administração pública, central ou local deve repartir responsabilidades, apoiar e assumir compromissos para a sua promoção, criando políticas públicas que promovam o acesso de todos os cidadãos à sua prática.

É hoje comumente aceite que foram as autarquias locais o motor do desenvolvimento desportivo local em Portugal, assumindo um papel preponderante no desporto nacional, sendo responsáveis por grande parte do investimento nacional em infraestruturas desportivas e no desenvolvimento de programas desportivos. Isto resulta, indubitavelmente, do facto de serem entidades mais próximas dos cidadãos e, como tal, as mais aptas para resolverem os problemas das suas populações, sendo aquelas que mais contribuíram e continuam a contribuir para o desenvolvimento do Desporto em geral (Joaquim, 2009).

No sentido do que temos vindo a discorrer, as autarquias locais são extremamente relevantes no contexto desportivo português, quer pelo impacto que sempre tiveram e 
continuam a ter no desenvolvimento de programas desportivos, quer no investimento que fazem ao nível das infraestruturas desportivas. Paipe (2016), apoiando-se em Pereira (2009), dá corpo a esta afirmação:

É nesta ótica, que os municípios sendo as entidades da administração estatal que mais próximas se encontram do cidadão, tem atribuições e competências fundamentais para a prossecução da missão do Estado no âmbito desportivo. Isto é, servir os cidadãos e as organizações, dar boas respostas às aspirações, necessidades e motivações, e contribuir para a melhoria da qualidade de vida das pessoas através da definição de políticas e oferta de serviços desportivos. (Paipe, 2016, p. 29)

É, portanto, neste contexto que o presente estudo se insere, com uma abordagem aos conceitos de desenvolvimento organizacional, governança e liderança, concomitantemente com o papel das estruturas municipais na concretização de políticas desportivas, sustentadas no planeamento e na estratégia.

A racionalização dos recursos públicos e uma melhor gestão do erário, resultam de novos modelos de governança e de uma nova sensibilização para o desenvolvimento sustentável e para a preservação do meio ambiente. As exigências por uma gestão mais eficiente e eficaz são hoje mais evidentes e incontornáveis.

A procura de níveis cada vez mais elevados" exige "dos decisores e líderes das organizações uma constante preocupação pela definição e implementação de políticas de desenvolvimento", sendo reconhecido ao desporto o seu papel enquanto "fenómeno social de enorme complexidade, onde a interação com os vários sectores de funcionamento da sociedade obriga a adaptações constantes aos pressupostos ambientais em que está inserido ou de que é dependente (Sarmento et al., 2011, p. 3-4).

Tendemos a concordar com Giacobbo (1997) no reconhecimento de que a atuação de uma organização com responsabilidades no desenvolvimento desportivo não se pode basear em pressupostos subjetivos, pouco fundamentados e de caráter pontual. Antes pelo contrário, a sua intervenção deve ser planeada, devidamente projetada e estruturada, pelo que se torna evidente a necessidade de desenvolver planos estratégicos.

Contudo, apesar da importância crescente do planeamento estratégico para a tomada de decisões nas organizações, facto é que o uso deste instrumento é diminuto, no que às autarquias locais diz respeito, visto a dificuldade em encontrar estudos científicos sobre esta matéria. 
Ainda assim, foi-nos possível perceber que existem algumas autarquias que possuem planos estratégicos de desenvolvimento desportivo, mas numa mera lógica de apresentação de atividades, infraestruturas e medidas, não indo muito além desta simples enumeração.

A revisão de literatura sobre o papel das autarquias no desenvolvimento do desporto em Portugal é substancial (Delgadinho, 2011; Ferrão, 1999; Januário, Sarmento, \& Carvalho, 2009). Entretanto, quando se busca a relação das autarquias com o setor produtivo e com as universidades, verifica-se uma grande lacuna. Este gap se apresenta tanto em estudos que revisamos em Portugal como também no Brasil. Desta forma, o presente estudo buscou ouvir diferentes agentes sociais que movimentam a hélice de desenvolvimento (Etzkowitz, 2005; Etzkowitz \& Leydesdorff, 1995; Etzkowitz \& Leydesdorff, 2000; Etzkowitz \& Zhou, 2006; Silva, Sarmento \& Netto, 2010). A hélice de desenvolvimento a que estes autores se referem se consubstancia na relação entre os governos, as empresas, as universidades e as organizações híbridas.

Este estudo teve por objetivo descrever as principais perceções de dirigentes associativos, políticos e empresários sobre a atuação das autarquias locais e dos demais agentes desportivos, com quem se relacionam, sobre o desenvolvimento do desporto em Portugal.

\section{Metodologia}

Todo o processo de investigação tem de iniciar pela definição clara da metodologia e dos métodos a utilizar. Sem esta definição inicial, não é possível encontrar as soluções para os problemas que nos propomos a indagar (Almeida \& Pinto, 1986). De acordo com Bell (1997, p. 14): "uma investigação é conduzida para resolver problemas e para alargar conhecimentos, sendo, portanto, um processo que tem por objetivo enriquecer o conhecimento já existente".

Das várias metodologias existentes, qualitativas e quantitativas, no processo de investigação efetuado, e que está na base do presente estudo, recorremos à etnometodologia, um dos métodos mais importantes da investigação qualitativa.

Enquanto corrente sociológica, a etnometodologia surge nos anos 1960, na Califórnia, com a obra de Garfinkel (2012) "Studies in Ethnomethodolgy", datada de 1967. Na base do pensamento de Garfinkel, estão as teorias da ação de Parsons, a fenomenologia social de Schutz, o interacionismo simbólico e as influências da "Escola de Chicago". Ainda assim, só a partir de meados da década de 1980 passou a ser amplamente estudada (Araújo, 2012). 
Esta nova corrente veio romper com a visão tradicional do pensamento sociológico, fundamentando a sua pesquisa no estudo dos etnométodos, ou seja:

Os métodos de que todo indivíduo, erudito ou não, utiliza para interpretar e pôr em ação na rotina de suas atividades práticas cotidianas, a fim de reconhecer seu mundo, tornando-o familiar, ao mesmo tempo em que o vai construindo. (Silva C. \& Votre, 2012, p. 12-13).

Silva E., citando Haguette (2013, p. 7-8), defende que a "etnometodologia se inscreve na tradição do interacionismo simbólico ao tentar ver o mundo através dos olhos dos atores sociais e dos significados que eles atribuem aos objetivos e às ações sociais que desenvolvem". De acordo com o mesmo autor, a palavra etnometodologia deriva dos termos folks e methods, significando "métodos de organização do mundo ou capacidades com as quais as pessoas desenvolvem uma compreensão dos outros e das situações sociais", sendo a etnometodologia a reflexão desses atores sociais sobre as suas ações.

Por sua vez, para Coulon, citado por Silva E. (2013, p. 7), a “etnometodologia pode ser definida como a pesquisa empírica dos métodos que os indivíduos utilizam para dar sentido e ao mesmo tempo realizar as suas ações quotidianas”. Complementando esta definição, Becker, citado pelo mesmo autor, afirma que a "etnometodologia permite compreender o modo como as pessoas percebem, explicam e descrevem a ordem no mundo em que habitam", sendo desta forma que, permanentemente, estabelecem e reconstroem a realidade. Para este autor, "na etnometodologia o importante é observar as atividades práticas das pessoas mediante as quais seja possível revelar os métodos pelos quais essas pessoas agem. (p.7).”

A etnometodologia está interessada no papel ativo e criativo dos atores sociais, na construção de seu quotidiano, dedicando especial atenção aos detalhes dessa construção e aos significados que ocorrem mediante cada nova interação, em vez de os entender como meros reprodutores das influências que recebem da sociedade. Perante isto, são vários os autores que entendem a etnometodologia como um caminho disruptivo (Silva C. et al., 2015, p. 220).

Os instrumentos utilizados na coleta dos dados foram a observação participante, ofocus group e a entrevista semiestruturada.

A observação participante ocorreu na autarquia de Santo Tirso. Em função de um dos pesquisadores ser funcionário dessa autarquia, houve necessidade de assumir uma postura de participante-observador (Cicourel, 1995), de forma a promover o distanciamento necessário para obter uma visão em perspetiva. Inevitavelmente, com a utilização da observação 
Machado, J. E. O., Sarmento, J. P., \& Silva, C. A. F. da. (set./dez. 2020). Perceções de lideranças sobre a atuação das autarquias locais no desenvolvimento do desporto em Portugal

participante, o investigador baseia a sua intervenção na convivência com a pessoa ou grupo em estudo, uma vez que só esta propicia as condições necessárias para que o processo de observação possibilite um entendimento genuíno dos factos, que de outra forma, através do recurso a outro instrumento de recolha, não nos seria possível colher. Como principais passos, para aplicação deste instrumento, elencamos os seguintes: escolha da situação a observar; observação e registo; análise e interpretação dos dados recolhidos. Por fim, no caso em apreço, foi utilizado como técnica de recolha a utilização de relatórios de observação. Estes dados foram sendo registados à medida que resultavam de reflexões do investigador perante diversas situações observadas no cotidiano da autarquia.

O focus group (Kreuger, 1988) foi realizado com empresários desportivos (ED) e dirigentes associativos (DA). Após a transcrição das entrevistas, que foram filmadas, analisamos o conteúdo das discussões, procurando tendências e padrões que se apresentaram nos relatos, iniciando-se o processo com uma comparação das palavras usadas e a ênfase ou intensidade dos comentários dos participantes. Atentamos para o fato de que a análise destes dados requer julgamento e habilidade. A narrativa fornecida por grupo de participantes foi resumida textualmente, no entanto, consideramos o contexto rico, além da mera transcrição do texto. Tendo por base as reflexões que fomos dando conta, a nossa opção passou por entrevistar os dirigentes associativos de Santo Tirso, de associações federadas e não federadas, por entendermos que estes agregam em si as diversas dimensões dos vários agentes desportivos (pais, atletas, treinadores, dirigentes, seccionistas, entre outros). Esta escolha fundamentou-se na dimensão da organização, nos seus resultados, diversidade de oferta desportiva, localização e apoio financeiro concedido pela autarquia, nos últimos anos, tendo sido realizados dois focus groups, divididos entre associações federadas e não federadas.

Entendemos, ainda, realizar outro focus group com empresas desportivas sediadas no concelho que desenvolvem a sua atividade na promoção e dinamização de eventos desportivos, reconhecendo a importância que têm para a definição de uma estratégia desportiva concelhia concertada e virada para a potenciação do turismo desportivo.

As entrevistas semiestruturadas foram realizadas, individualmente, com os decisores políticos locais (DPL). Como principais passos para a implementação deste instrumento, identificamos os seguintes: a seleção dos entrevistados, o planeamento da entrevista, a seleção e competência dos entrevistadores, o controlo do decurso da entrevista e, por fim, a interpretação e análise dos resultados. Das três principais formas de entrevista, entenda-se, a 
entrevista fechada, semiestruturada e aberta, a nossa investigação optou pela entrevista semiestruturada, onde combinamos perguntas fechadas, previamente organizadas e definidas, com a possibilidade ao entrevistado divagar sobre o tema em questão. Assim, o investigador/entrevistador seguiu um conjunto de questões previamente definidas, mas teve a liberdade de, sempre que achou oportuno, formular novas questões adicionais sobre temas previamente aflorados, que não tinham sido claramente expostos ou que mereciam um maior aprofundamento.

$\mathrm{Na}$ organização e análise dos resultados, foram estabelecidas três categorias, a partir da identificação dos termos indiciais nas ideias veiculadas nos discursos dos entrevistados. Os indícios foram então organizados em torno das categorias. Utilizamos o termo "indício" em função da herança etnometodológica e da perspetiva da indicialidade dos discursos, que necessitam estar situados no contexto de forma a se tornarem relatáveis. Desta forma, as categorias surgiram a partir dos indícios encontrados nas falas dos entrevistados, e, posteriormente, formalizadas após a leitura flutuante. As categorias respeitaram os critérios sugeridos por Bardin (2011) para sua efetivação a saber: 1. Exclusão mútua: a ideia não poderia ser capaz de compor mais de uma categoria; 2. Homogeneidade: a construção das categorias não permitia que ideias com significados diferentes fizessem parte da mesma tipologia; 3 . Relevância: as categorias foram criadas após a classificação análoga das ideias veiculadas, de forma que surgissem a partir dos dados coletados, ou seja, não foram construídas a priori; 4. Objetividade e fidelidade: uma ideia não poderia ser categorizada de outra forma, estabelecendo o critério de confronto e entrada na categoria.

\section{Revisão de literatura}

\subsection{A hélice de desenvolvimento: planeamento, desporto e sustentabilidade}

Etzkowitz e Leydesdorff (1995) constroem um modelo teórico e sociológico de desenvolvimento. Utilizam a imagem da hélice e as relações entre suas pás como impulsionadores do desenvolvimento. O modelo da hélice tríplice (triple helix) é composto por três atores principais: a universidade, o governo e a empresa. A partir da ideia de sociedade do conhecimento, o referencial teórico da hélice tríplice elenca a universidade como protagonista no processo de desenvolvimento de regiões (Etzkowitz, 2005; Etzkowitz \& Leydesdorff, 1995; Etzkowitz \& Leydesdorff, 2000; Etzkowitz \& Zhou, 2006. Silva, Sarmento \& Netto, 2010), 
diferentemente de outros modelos que preconizam o Estado (Sábato \& Mackenzie, 1982) ou as empresas (Lundvall, 1992; Nelson, 1993).

A literatura apresenta três possíveis modelos de hélice tríplice. O primeiro modelo tem na figura do Estado o protagonista das ações de desenvolvimento, englobando tanto as universidades como as empresas. Este modelo é adotado principalmente nos países do leste europeu e em países asiáticos.

O segundo modelo, denominado de lassez-faire, é utilizado principalmente nos Estados Unidos, e tem uma perspetiva de independência entre os três atores. No terceiro modelo, os três principais atores da hélice se inter-relacionam formando áreas de interseção, que podem incluir ações conjuntas entre governo-universidade, empresa-governo, universidade-empresa, e também ações conjuntas entre os três e as organizações híbridas (organizações nãogovernamentais, fundações, organizações sociais, autarquias, entre outras) (Etzkowitz \& Zhou, 2006; Etzkowitz \& Leydesdorff, 2000).

No campo do desporto, alguns autores têm se dedicado às questões do desporto como factor de desenvolvimento. $O$ desporto exerce influência na dinâmica e geração de receitas importantes para as economias locais e nacionais. Os pressupostos do modelo da hélice tríplice têm sido utilizados na inovação de processos e alianças intersetoriais no desporto (Silva, Sarmento \& Netto, 2010; Sarmento et al., 2011; Steigleder et al., 2020).

Independentemente do modelo da hélice tríplice, o planeamento é essencial tanto para as organizações públicas, privadas ou híbridas. Planear compreende a projeção de um conjunto de ações para atingir um determinado resultado. É a capacidade de atuar de forma integrada, com uma estratégia inclusa, envolvendo a escolha de um curso de ações e a determinação de quando e como devem ser realizadas (Terence, 2002).

O planeamento é, assim, entendido como uma função primordial de qualquer organização, sendo a fase do processo de gestão onde são tomadas decisões sobre os propósitos, as políticas, as estratégias, os programas e os planos que direcionam as atividades das organizações. Trata-se de um processo contínuo e dinâmico que é afetado pelo meio ambiente no qual a organização está inserida (Giacobbo, 2007).

Dentro dos vários níveis de planeamento existentes, encontramos o planeamento estratégico (Barambão, 2012; Pires, 2005). Este tipo de planeamento trata das principais questões da organização, analisando o ambiente interno e externo, por forma a determinar os objetivos e as ações a adotar por toda a organização. Trata-se, portanto, de um processo amplo 
e global, com um horizonte temporal de longa duração, da responsabilidade dos dirigentes da organização (Barambão, 2012).

O planeamento estratégico tem-se concentrado, principalmente, em organizações do setor privado, onde o ambiente operacional é em regra competitivo, onde o lucro é a força motriz por detrás da necessidade de planear. Nas organizações do setor público, o principal driver não é o lucro, no entanto, a necessidade de uma gestão mais racional do erário, satisfazendo as necessidades das populações, dentro de um determinado orçamento, trazem a este conceito uma enorme relevância e aplicabilidade (Kriemadis \& Theakou, 2007).

Portanto, podemos assegurar que a necessidade de planeamento estratégico é tão pertinente no setor público como no setor privado. Por conseguinte, entendemos ser inevitável que todas as organizações públicas passem a ser geridas com recurso a planos estratégicos, caso contrário, estarão entregues à sua própria sorte, obrigadas a aceitar o futuro, seja ele qual for, sem capacidade de resposta aos estímulos e surpresas do ambiente externo. Só através da consciencialização da sua necessidade será possível ao setor público estar preparado para as exigências do século XXI, planeando e não reagindo.

As demandas sociais neste século passam necessariamente pela ideia de sustentabilidade. Considerando que um desenvolvimento sustentável pressupõe a preocupação não só com o presente, mas com a qualidade de vida das gerações futuras, há a clara necessidade de proteger os recursos vitais e incrementar fatores de coesão social e equidade, garantindo um crescimento económico amigo do ambiente e das pessoas.

Com o intuito de dar resposta a estas e muitas outras questões, Elkington concebeu, em 1997, o conceito do Triple Bottom Line, defendendo que todas as organizações no seu processo de decisão e no decurso da sua atividade empresarial devem respeitar as dimensões económicas, sociais e ambientais, procurando a prosperidade económica, mas respeitando a justiça social e o meio ambiente. Para o autor, o objetivo deste instrumento é promover o desenvolvimento sustentável das organizações, com claras vantagens para a sustentabilidade global (Soares, 2006).

Na ótica da dimensão ambiental, uma organização sustentável procura reduzir os impactos negativos causados pelo desenvolvimento da sua atividade, respeitando, entre outros, a legislação ambiental e a ecoeficiência dos seus negócios (Soares, 2006). 
Perante isto, torna-se evidente que todas as organizações deverão caminhar no sentido de criar modelos de gestão por competências sustentáveis, voltadas não só para a dimensão económica, mas, simultaneamente, para as responsabilidades sociais e ambientais.

Os defensores deste conceito acreditam que, desta forma, a organização não só será mais sustentável como mais eficiente e rentável, uma vez que a busca pela sustentabilidade promove a inovação, motiva para o desenvolvimento de novos produtos, processos e tecnologias e, ao nível dos recursos humanos, dá-lhes maiores competências e apetência para as mudanças organizacionais (Oliveira, 2012; Paz \& Kipper, 2016; Soares, 2006). No seio da administração pública, são vários os defensores da utilização deste instrumento e da sua pertinência para a gestão pública.

\subsection{Desenvolvimento organizacional e estratégia}

O desenvolvimento organizacional é uma resposta da organização às mudanças que lhe são impostas por fatores externos, compreendendo um esforço em alterar, na estrutura da organização, atitudes, valores e comportamentos para que, dessa forma, ela consiga se adaptar, rapidamente e com eficiência às novas conjunturas económicas, problemas e desafios que lhe são colocadas por um mundo em constante evolução e mudança.

A velocidade a que as transformações ocorrem na vida atual exige que as organizações sejam capazes de se adaptar facilmente à mudança. Desta forma, o desenvolvimento organizacional é entendido como uma ferramenta que permite implementar um programa de transformação planeada em prol da organização, com base em critérios de adaptabilidade e flexibilidade, tentando minimizar os danos causados pelas mutações que ocorrem no mundo exterior, que têm, necessariamente, impacto no seio da organização e do seu ambiente (Pires, 2005).

No entanto, pela própria condição humana, podemos assumir que toda mudança gera resistência, interna e externa, já que o ser humano é adverso à mesma. Esta situação é facilmente explicada, não carecendo de estudos antropológicos aprofundados, para percebermos que a mudança provoca em nós um desequilíbrio interno, pelo medo do desconhecido e por nos obrigar a sair da conhecida "zona de conforto".

Para que haja mudança, não basta que se altere a estrutura da organização, é necessário que se considerem quatro variáveis básicas, como o ambiente, a organização, o grupo e o 
indivíduo. Trabalhar o processo de mudança organizacional é complexo, significativo, profundo e exige um correto planeamento, interpretação, conhecimento da cultura da organização, consciência do impacto do processo na organização e congruência entre os objetivos a atingir e o desenvolvimento organizacional pretendido (Lobos, 1975).

Perante isto, parece-nos que se reveste da maior importância a preocupação dos líderes com o desenvolvimento organizacional, pois reconhecemos a organização como um sistema social, que interage entre si, influenciada por fatores internos e externos, refletindo as suas decisões no meio em que se insere e vice-versa, sendo influenciada pelo modo como as suas políticas inferem na sociedade.

Além disto, sendo o planeamento estratégico um processo de desenvolvimento complexo, composto pelos propósitos da organização, pelas suas estratégias e que tem de ser refletido em ações práticas (Terence, 2002), ao longo do seu decurso haverá, seguramente, a necessidade de se procederem a ajustes e alterações. Na maioria das vezes será necessário que a estrutura da organização sofra algumas alterações e que os indivíduos contribuam para a sua implementação, o que inferirá na cultura organizacional vigente e obrigará os colaboradores a saírem da "zona de conforto", para que seja possível uma plena execução do plano e, de acordo com a monotorização e avaliação, efetuadas as necessárias correções de trajetória.

Por maioria de razão, não nos parece possível versar sobre planos estratégicos sem abordar o conceito de estratégia per si. Epistemologicamente a palavra "strategos" combina dois termos "strato" e "ag", que significam, respetivamente, "exército" e "liderar" (Amador, 2014; Terence, 2002).

Nestes termos, é possível perceber que a palavra estratégia tem uma origem bélica, sendo durante milhares de anos utilizada, preferencialmente, por militares. Uma das primeiras referências à sua origem militar é na obra de literatura "Arte da Guerra" de Sun Tzu (Amador, 2014).

No seio das organizações, a utilização do conceito de estratégia surge por volta da década de 1960, com o objetivo de indicar o caminho que a organização pretende seguir para atingir determinadas metas e objetivos.

Assim, a palavra estratégia passou a estar associada ao conceito de planeamento, sendo aceite que tenha por finalidade a formulação de um plano que reúna os objetivos, as políticas e as ações de uma organização. Uma estratégia bem formulada permite uma correta afetação de 
recursos, uma correta definição das ações e uma correta determinação dos procedimentos, inerentes ao processo de planeamento (Amador, 2014).

Portanto, a estratégia é, basicamente, o decurso da ação adotada pela organização, representando uma escolha e seleção do caminho a seguir, com respeito pelos aspetos internos e externos da organização. Uma visão estratégica envolve uma ampla noção de espaço e tempo, pelo que será vital compreender as consequências futuras das decisões tomadas no presente, sendo crucial que se cultive o foco nos objetivos e nos resultados futuros (Chiavenato \& Sapiro, 2009; Teixeira, 2011).

\subsection{Governança e o papel das autarquias locais de Portugal no desenvolvimento desportivo}

Nos dias que correm, o conceito de governança tem-se tornado num tópico bastante popular. Não sendo um conceito jurídico, surge pela primeira vez em documentos oficiais do Banco Mundial, no início da década de 1990, ficando associado, na sua génese, à Ciência Política e às Relações Internacionais (Gonçalves, 2005).

De acordo com este autor, segundo a definição do Banco Mundial, a governança é:

O exercício da autoridade, controle, administração, poder de governo (...) e a maneira pela qual o poder é exercido na administração dos recursos sociais e económicos de um país visando o desenvolvimento", implicando ainda "a capacidade dos governos de planear, formular e implementar politicas e cumprir funções (Gonçalves, 2005).

Portanto, em sentido amplo, a governança é entendida como o exercício do poder na gestão de uma organização, tendo por função principal a tomada de decisões, alicerçada em conceitos como responsabilidade, regras e políticas, comunicação e transparência.

Pelo tema de nosso estudo, é facilmente entendível que abordar o conceito de governança é vital, nomeadamente pelo reconhecimento do poder decisório das autarquias locais nos domínios da atividade física e do desporto, legitimado pelo ordenamento jurídico português.

O enquadramento legal do Desporto nas autarquias locais está disperso em três diplomas: a Lei de Bases da Atividade Física e do Desporto, Lei n. 5/2007, de 16 de janeiro; Lei Quadro de Competências e Regime Jurídico de Funcionamento dos Órgãos dos Municípios e das Freguesias, Lei n. ${ }^{\circ}$ 169/199, de 18 de setembro; Regime Jurídico das Autarquias Locais,

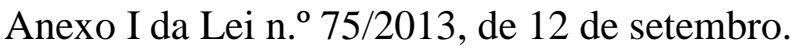


Daqui resulta que, na Lei, o Desporto consta entre as atribuições e competências das autarquias locais, sendo exemplos disso o disposto na alínea f) do $\mathrm{n}^{\circ} 2$ do artigo $23^{\circ}$, e o disposto na alínea d) do $n^{\circ} 2$ do artigo $7^{\circ}$, do Anexo I da Lei $n^{\circ} 75 / 2013,12$ de setembro: "Os municípios dispõem de atribuições, designadamente, nos seguintes domínios [...] Tempos livres e desporto;" "As freguesias dispõem de atribuições designadamente nos seguintes domínios [...] d) Cultura, tempos livres e desporto", respetivamente.

A Constituição da República Portuguesa enuncia três espécies de autarquias locais: as freguesias, os municípios e as regiões administrativas. Destas, apenas existem efetivamente a freguesia e o município, que estão constitucionalmente previstas no título respeitante ao Poder Local, dispondo de património, finanças, receitas, poder regulamentar e quadros de pessoal próprio.

Os municípios são a autarquia local que sempre teve uma importante intervenção no âmbito do Desporto, sendo os principais promotores e dinamizadores do desenvolvimento desportivo local e, por maioria de razão, os principais promotores e dinamizadores do desenvolvimento desportivo nacional (Carvalho, 1994). É, portanto, inquestionável a forte aposta que os municípios fazem no Desporto, seja numa lógica de promoção da atividade física, saúde e bem-estar, seja numa lógica de afirmação territorial e de promoção do que de melhor têm para oferecer.

Desta forma, somos da opinião de que, tal como no passado, as autarquias locais são, no presente e serão no futuro, extremamente importantes para o desenvolvimento do Desporto, a todos os níveis e em todas as suas dimensões. Neste sentido, Pires (2000), citado por Carvalho (2007) afirma que "a autarquia terá uma responsabilidade crescente na configuração do Desporto do futuro, sendo colocada uma grande carga de responsabilidade e confiança no desenvolvimento da estratégia para o desenvolvimento desportivo" (p. 24).

Outra questão consensual é a necessidade de as autarquias locais desenvolverem estratégias, processos e mecanismos para reforçar a sua atuação no âmbito do Desporto, por forma a poderem catapultar e promover o tão apregoado desenvolvimento desportivo dos seus territórios, nomeadamente através da realização de planos estratégicos de desenvolvimento desportivo, identificando, balizando e planeando, de uma forma clara e concisa, toda a sua atuação neste âmbito.

O Desporto nas autarquias locais não pode mais ser visto de forma isolada e à mercê da vontade dos decisores políticos. Hoje, a exigência é maior. A crise e o aperto financeiro que o 
Machado, J. E. O., Sarmento, J. P., \& Silva, C. A. F. da. (set./dez. 2020). Perceções de lideranças sobre a atuação das autarquias locais no desenvolvimento do desporto em Portugal

país sofreu tiveram consequências positivas, se é que se pode expor desta forma, particularmente na responsabilidade e na exigência com que se gere o erário. Atualmente, todos defendemos um desenvolvimento sustentável do Desporto, só possível de alcançar através de um planeamento estratégico do fenómeno desportivo.

\section{Resultados e discussão}

As autarquias dispõem de um vasto lastro de atribuições e competências no domínio do Desporto. Aliás, chegámos à conclusão de que os municípios são a autarquia local que sempre teve uma importante intervenção no Desporto, sendo os principais promotores e dinamizadores do desenvolvimento desportivo local e, por maioria de razão, os principais promotores e dinamizadores do desenvolvimento desportivo em Portugal.

\subsection{Categoria}

a) Autarquias, Empresas e Estado

$1^{o}$ indício: importância das autarquias locais

Esta posição foi atestada pelos decisores políticos locais (DPL), quando entrevistados:

"a verdade é que têm sido os Municípios que têm tido um trabalho muito importante na diversificação, promoção e estímulo do desporto em geral, conforme a sensibilidade dos vários autarcas que estiveram à frente das autarquias nos últimos 40 anos". "As autarquias (...) têm-se substituído, nas últimas três ou quatro décadas, ao Estado, digamos, à tutela. Se não fossem as autarquias, provavelmente o estado da arte do Desporto e da atividade física em Portugal seria trágica" (DPL).

Asseveram, ainda, que "no que concerne ao Desporto (...), se não fossem os Municipios, o Desporto não teria a promoção que tem. Sem dúvida, os municípios têm um papel preponderante, substituindo-se completamente ao Estado" (DPL).

É, portanto, indiscutível a forte aposta que os municípios fazem na área do Desporto, seja numa lógica de promoção da atividade física, saúde e bem-estar, seja numa lógica de afirmação territorial e de promoção do que de melhor têm para oferecer.

Estas posições corroboram Pires (2000), citado por Soares (2009, p. 24 e 25), quando este declara que "a autarquia terá uma responsabilidade crescente na configuração do Desporto 
Machado, J. E. O., Sarmento, J. P., \& Silva, C. A. F. da. (set./dez. 2020). Perceções de lideranças sobre a atuação das autarquias locais no desenvolvimento do desporto em Portugal

do futuro, sendo colocada uma grande carga de responsabilidade e confiança no desenvolvimento da estratégia para o desenvolvimento desportivo".

$2^{\boldsymbol{o}}$ indício: ausência de estratégias comuns (nacional vs. municipal)

Os entrevistados também assumem que a responsabilidade das autarquias locais pode representar em si um problema, na medida em que se torna difícil de operacionalizar e compatibilizar uma estratégia política municipal, com uma estratégia política intermunicipal, regional ou nacional, colocando o âmago da questão na dificuldade de definir o ponto de encontro, em virtude da ausência de estratégias comuns:

"até que ponto é que estratégia das políticas públicas municipais do Desporto se encontram com a ausência de estratégia a nivel nacional? (...) A ausência de uma estratégia desportiva municipal, (...), resulta depois neste estado de coisas, onde cada um vai fazendo coisas, (...), mas falta algo que as ligue" (DPL).

Esta falta de ligação e planeamento provoca o aparecimento de assimetrias regionais e proporciona que "o país não seja uniforme e, portanto, não tenha uma política desportiva uniforme a nivel nacional, geral e universal." (DPL).

A visão dos decisores políticos locais é corroborada pelos empresários desportivos (ED): “os Municípios e o Estado têm um papel fundamental na prática do Desporto, na colaboração e na promoção de eventos desportivos para a sociedade civil” (ED).

Fica evidenciado nestas falas a falta de um espaço de busca de consenso. Diversos autores destacam este espaço como fundamental para a inovação e o desenvolvimento. Teríamos três espaços fundamentais: o do conhecimento, o do consenso e o da inovação. Sem o espaço do consenso não há inovação, pois é nele que os diferentes atores se aproximam e buscam soluções em conjunto para os desafios (da Silva, Terra, \& Votre, 2008; Etzkowitz, 2005; Etzkowitz \& Leydesdorff, 1995; Etzkowitz \& Leydesdorff, 2000; Etzkowitz \& Zhou, 2006; Silva, Sarmento \& Netto, 2010).

$\mathbf{3}^{\circ}$ indício: parcerias público-privadas

Os empresários desportivos (ED) reconhecem que há uma grande necessidade de se estabelecerem parcerias público-privadas e, desta forma, que os Municípios e o Estado colaborarem com as empresas na promoção da atividade física e do Desporto, afirmando que 
"os Municípios têm cada vez mais de se abrir a parcerias, para que as entidades privadas tenham vontade de fazer e devem existir mecânicas facilitadoras, no sentido de apoiarem as organizações (...)" (ED), e que "se o Estado e os Municípios apostassem mais na promoção de atividades desportivas, as pessoas gastavam menos nas farmácias.” (ED).

Reforça-se aqui as ideias em relação às parcerias entre dois ou mais atores da hélice tríplice (Etzkowitz \& Leydesdorff, 2000; Etzkowitz \& Zhou, 2006).

$\mathbf{1}^{\mathbf{0}}$ indício (reforçado pelos dirigentes associativos)

Os dirigentes associativos (DA) também são unânimes no reconhecimento do importante papel dos municípios no desenvolvimento desportivo local e nacional (Ferrão, 1999; Joaquim, 2009), entendendo que devem ser as autarquias, por razões de proximidade com as coletividades, a ter este papel: "De facto, o Município deve apoiar o mais possível as coletividades, na medida em que é uma função do Estado, quanto mais não seja, ao nível das autarquias, pela proximidade do poder político local”. (DA).

Defendem, ainda, que o associativismo desportivo exerce uma função de complementaridade à função do Estado e dos municípios, auxiliando-os na execução das suas competências e atribuições, como é visível na seguinte declaração: "as coletividades exercem uma função (...) não de substituição, mas auxiliar da própria função social do Estado (...) Não deve haver uma dependência das associações, instituições ou coletividades face à autarquia." (DA).

Destarte, afirmam que os municípios e o Estado devem

"auxiliar o mais possível (...) as coletividades e instituições que, (...) numa lógica de atribuição de subsídios, (...) de uma forma abnegada e voluntariosa, se dedicam a essa função que competiria ao Estado e depois, de uma forma hierárquica, às autarquias, mas não numa lógica de total subsidio dependência, até porque os recursos não são imensos e, portanto, não será possível acorrer a todos." (DA).

$4^{o}$ indício: coordenação entre entidades públicas e privadas

Os dirigentes associativos (DA) referem-se à necessidade de uma melhor coordenação entre entidades públicas e privadas, defendendo que devem ser os municípios a assumir esse papel de destaque na coordenação das infraestruturas desportivas, bem como de tudo o que gravita à volta do fenómeno desportivo, dentro do seu território:

"os municipios (...) ao nivel de infraestruturas (...) assumem já um papel importante, mas têm de assumir um papel ainda mais efetivo, principalmente na coordenação de recursos (...), porque muitas vezes fazem-se coisas duplicadas. É importante o assumir deste papel por parte dos municípios, dada a proximidade que têm com os clubes." (DA). 
Esta fala ressalta o papel do Estado nas ações de desenvolvimento, assim como o fazem Sábato e Mackenzie (1982).

\subsection{Categoria}

b) Planeamento, Desporto e Desenvolvimento Sustentável

No que concerne ao desenvolvimento desportivo, à relevância do planeamento estratégico e a sua relação com o desenvolvimento sustentável, o Desporto nas autarquias locais não pode mais ser visto de forma isolada e subjacente à vontade discricionária dos decisores políticos. Hoje, a exigência é cada vez maior de aproximação e inter-relação com outros agentes.

$\mathbf{5}^{\mathbf{0}}$ indício: falta de planeamento estratégico para o desenvolvimento sustentável

Em resultado da análise efetuada às entrevistas aos decisores políticos locais, ficamos a perceber que nenhum dos municípios possuía um Plano Estratégico de Desenvolvimento Desportivo. Contudo, todos reconheceram a sua relevância para um verdadeiro desenvolvimento desportivo no concelho em que vivem. Aliás, reforçaram e reconheceram a necessidade de existirem planos de âmbito regional e nacional que, até a data, não existem.

No que à sustentabilidade diz respeito, esta é uma preocupação que está no pensamento dos decisores políticos, no sentido de as infraestruturas desportivas acompanharem esta tendência e inovação:

"as infraestruturas devem acompanhar o desenvolvimento sustentável, seja através da gestão racional de água, de painéis solares, etc. Portanto, as infraestruturas também devem ser sustentáveis (...), ou seja, (...) as infraestruturas desportivas, infraestruturas físicas do desporto, obviamente que devem acompanhar a modernidade relativamente à eficiência energética, à sua acomodação, à sua dignidade e qualidade para a prática do Desporto. (...) Quando eu falo numa política sustentável, quando falo até de economia circular, ou quando falo da mobilidade suave, das alterações climáticas, de todas as temáticas e políticas de uma sociedade desenvolvida sustentavelmente, o Desporto faz todo o sentido, porque é uma parte integrante deste modelo". (DPL).

Neste sentido, acreditam que "o grande desafio das sociedades modernas, nos próximos anos, será o desenvolvimento sustentável, (...). Esta será a linha que vai definir as cidades que vão sobreviver ou não neste mundo tão competitivo." (DPL); pelo que defendem que o processo de requalificação e de adaptações das instalações desportivas mais antigas, aos novos modelos 
de adaptação climática e ao desenvolvimento sustentável, pode não ser possível ou viável, advogando que "o que se construir a partir de agora deve ter essas preocupações ambientais muito bem definidas" (DPL), reconhecendo que os equipamentos podem ser mais dispendiosos na sua execução, mas que trazem consigo ganhos financeiros e ambientais impactantes e mensuráveis.

Sobre este tema, a concordância foi a tónica dominante:

"este é o futuro, portanto, a sustentabilidade ambiental é um discurso que já está na práxis política de hoje, (...) e que vai marcar o futuro das cidades nos próximos 20, 30, 40, 50 anos (...) o que quer dizer que é uma pena se as instalações desportivas e o desporto não acompanharem a evolução." (DPL).

Pelo exposto, é para nós seguro afirmar que o Desporto não pode alhear-se desta realidade e terá de efetuar a sua intervenção de uma forma sustentável e preocupada com o impacto nas gerações futuras (Oliveira, 2012). Portanto, também a administração pública, “enquanto gestora de bens e recursos públicos precisa (...) de dedicar atenção e executar ações direcionadas ao desenvolvimento sustentável buscando um modelo que agregue a promoção económica, a preservação e conservação ambiental e a preocupação social”. (Venturini \& Lopes, 2015, p. 3).

Nesta linha de pensamento, o planeamento estratégico é para nós fundamental, ou seja, na nossa opinião o desenvolvimento sustentável só pode ocorrer quando temos uma estratégia bem formulada, que permita uma correta afetação de recursos, uma correta definição das ações e uma correta determinação de procedimentos (Amador, 2014).

$\boldsymbol{6}^{\circ}$ indício: prevalência do político sobre o estratégico

Ainda assim, também não é menos verdade que a definição do planeamento e da estratégia, no seio das organizações, continua a ser algo complexo, como atestam os entrevistados: "Não raras vezes, por força da atividade que desenvolvemos, que é política, (...) a estratégia não prevalece (...), ou seja, a decisão política prevalece sobre aquilo que deveria ser uma estratégia." (DPL).

O planeamento é a função primordial de uma qualquer organização, sendo a fase do processo de gestão na qual são tomadas decisões sobre os propósitos, as políticas, as estratégias, os programas e os planos que direcionam as atividades das organizações, pelo que se trata de um processo contínuo e dinâmico (Giacobbo, 2007). 
Logo, é através do planeamento estratégico que podemos identificar o estado atual de uma organização e determinar o caminho que pretendemos que esta siga, embora, reconhecemos que este possa ser um processo complicado e de difícil execução pela discricionariedade da atividade política e da sua dependência do voto, faltando, por vezes, a coragem na administração pública para definir uma estratégia e cumprir o que foi previamente definido.

De qualquer forma, a classe política local não tem dúvidas que "a definição de uma estratégia, se depois for cumprida pela Câmara Municipal, se sobreviver à vontade e à decisão política, é um elemento fundamental de sucesso para o futuro." (DPL), posição com a qual concordamos inteiramente.

Estas reflexões são concomitantes com aquilo que os empresários desportivos (ED) e os dirigentes das associações (DA) reconhecem ser importante em termos de planeamento, estratégia e sustentabilidade. De acordo com estes, todas perfilham a necessidade de:

i) um maior investimento do Estado no Desporto, afirmação facilmente comprovada pela seguinte declaração: "o Estado tem de investir mais no Desporto e tem de se investir em condições" (DA);

ii) as preocupações com a sustentabilidade estão na ordem do dia, significado, inclusivamente poupança para as organizações, situação comprovada pelas seguintes declarações:

"até pelo marketing do evento, é uma das primeiras preocupações. A sustentabilidade é usada como uma forma de comunicação."; "Nós (...) somos uma empresa certificada ambientalmente. E ofacto de o sermos faz-nos trabalhar de melhor forma (...). Temos uma preocupação em termos de redução de produção de resíduos, redução dos consumos de energia, e isto gera poupança. (...). Temos também um investimento grande em formação e equipamento, com grande retorno, quer financeiro, quer ambiental. Ganha a empresa, ganha o planeta."; “A sustentabilidade é fundamental." (ED).

iii) o planeamento é também crucial para as empresas e para as associações, comprovado pelas seguintes declarações:

"relativamente aos planos estratégicos (...), os Municipios e o Estado têm de ter um plano estratégico. O que é que pretendem para o (...) concelho." (DA); "Concordo plenamente com a necessidade de existência de planeamento."; "Um plano estratégico é sempre importantíssimo. Portanto, há um plano, há uma estratégia e se a estratégia for boa, o plano funciona." (ED); "Hoje em dia não se faz praticamente nada sem planeamento. (ED) Tem de haver um planeamento, da estratégia e do investimento, o que é que deve ser investido e em que áreas." (DA). 
Machado, J. E. O., Sarmento, J. P., \& Silva, C. A. F. da. (set./dez. 2020). Perceções de lideranças sobre a atuação das autarquias locais no desenvolvimento do desporto em Portugal

Quanto aos passos a dar na construção de um plano estratégico, os dirigentes de associações (DA) sugerem que este deve "envolver toda a comunidade", "envolver os clubes e as associações, mas também as juntas de freguesias" e "depois o plano estratégico deveria ter o compromisso dos políticos para o implementar". Esta preocupação latente está diretamente relacionada a discricionariedade política e o facto de o plano estratégico poder não ser respeitado pela classe política. Aliás, este é o sentimento perpetrado pelas associações e pelos empresários, quando afirmam que

"Em Portugal temos esse grave problema. Muda o governo, muda tudo. Nas autarquias é igual, se a cor política for a mesma, a diferença de rumo não é muita, caso contrário já sabemos como é. (...). A verdade é que sempre senti que (...) era um bocadinho ao sabor do vento. Hoje é para ali, amanhã é para acolá, há muita discricionariedade política, que se sobrepõe a um plano estratégico." (DA).

\subsection{Categoria}

c) Governança

No que à governança diz respeito, este é um conceito que se tem tornado num tópico bastante popular (Gonçalves, 2005). Em sentido amplo, a governança é entendida como o exercício do poder na gestão de uma organização, tendo por função principal a tomada de decisões, alicerçada em conceitos como responsabilidade, regras e políticas, comunicação e transparência.

Também no Desporto existe governança, sendo definida

como o exercício do poder e da autoridade numa organização desportiva, incluindo a formulação de políticas, a determinação da missão da organização, regras de afiliação, regras de elegibilidade e poder regulatório de elegibilidade e poder regulatório dentro de um escopo determinado como local, nacional ou internacional (Pizzaro, 2017, p. 200).

No caso das autarquias locais, estas não são uma organização exclusivamente desportiva, mas têm competências e atribuições que decorrem diretamente da lei e que as legitimam para atuar no contexto desportivo. Desta forma, o conceito de governança é vital, nomeadamente pelo reconhecimento do poder de decidir das autarquias locais no domínio da atividade física e do Desporto, legitimadas pelo ordenamento jurídico português.

$7^{\circ}$ indício: dificuldade na definição de competências 
Identificada a pertinência desta questão, os decisores políticos consideram que o tema da governança é complexo, desde logo pela dificuldade na definição de quem tem a competência para o fomento da atividade desportiva:

"Nesse contexto, a nossa legislação (...) é muito generalista, diz que ao Estado compete o desenvolvimento das políticas públicas desportivas, depois a legislação autárquica, nas competências e atribuições, atribui os Municípios algumas dessas políticas, mas não diferencia, não diz, o que é que é do Estado, o que é que é dos Municípios e o que é que é das Freguesias. $O$ que é que compete ao movimento associativo, ao desporto profissional e outras entidades (...). Ou seja, há aqui uma grande lacuna legislativa, (...) para determinar quem é quem, quem faz o quê e com que dinheiro." (DPL).

Ainda assim, a opinião destes é universal no sentido de reconhecer a importância do papel da governança no Desporto, afirmando que:

"a governança é fundamental para criar condições de base e (...) tem um papel fundamental no sentido de definir regras muito claras para aquilo que se quer. Quer nas cidades, em termos de ordenamento do território, quer em termos de mobilidade, em termos de infraestruturas, em termos de urbanização, quer fundamentalmente criando novas regras para os clubes e que eles vão ter inevitavelmente de cumprir."(DPL).

$8^{\circ}$ indício: perspetiva de mudança em passos lentos

A sua conexão com o planeamento estratégico resulta "se no espaço de cinco a dez anos algum Governo decidir tomar como prioridade nacional a elaboração de um plano estratégico e afetar-lhe os meios financeiros necessários, (...) pois isso seria uma revolução (...).” (DPL).

Contudo, não acreditam nesta solução, pelo que entendem que iremos continuar a "evoluir por pequenos passos e nos mesmos moldes em que temos evoluído até aqui" (DPL), não vendo grandes alterações ao nível da política nacional, no que a esta matéria diz respeito.

Existe um grau de dificuldade que os municípios têm para alterarem paradigmas e implementarem novas visões, como atestam os entrevistados: “A alteração de paradigmas e a implementação de novas visões não é fácil, (...) é muito difícil e quase impossível (...)”, acreditando que "não é possível ir muito mais além daquilo que já fazemos atualmente." (DPL).

Toda a organização possui uma cultura própria, podendo ser entendida como uma expressão cultural que compreende um conjunto vasto de elementos, como por exemplo, os hábitos, valores e crenças, que formam a identidade dessa organização. Essa cultura pode ser 
visível, através de normas e regras explícitas, ou invisível, compreendendo os elementos da cultura da organização que não estão escritos, mas que representam práticas habituais.

Ora, a velocidade a que as transformações ocorrem na vida atual exige que as organizações sejam capazes de se adaptarem facilmente à mudança, surgindo como resposta o conceito de desenvolvimento organizacional. Contudo, pela condição humana, podemos assumir, logo à partida, que toda a mudança origina resistência, interna e externa, já que o ser humano é adverso à mesma. Esta situação é facilmente explicada, não carecendo de estudos antropológicos aprofundados, para percebermos que a mudança provoca em nós um desequilíbrio interno, pelo medo do desconhecido e por nos obrigar a abandonar a chamada "zona de conforto".

Estas afirmações são corroboradas pelos decisores políticos, sendo que a opinião mais forte vai no sentido de que no Desporto "como em tudo na vida, ou se tem uma grande capacidade de adaptação à mudança, que é quase estratosférica, ou então não conseguimos evoluir." (DPL). Além disto, afirmam ainda que é preciso perceber que o "desenvolvimento organizacional depende também muito daquilo que é a visão estratégica do município em termos políticos.”(DPL).

Contudo, afirmam, pela sua experiência,

"que aquele que tenta imprimir um ritmo de mudança permanente é sempre olhado de soslaio, (...) como alguém como que, pondo em causa os processos, põe em causa as pessoas (...). Nós fulanizamos permanentemente, ou seja, o incremento da mudança numa organização é sempre visto como um ataque à pessoa e não um ataque aos métodos de trabalho da pessoa. Isto é muito complicado.", assegurando que "mudar é (...) muito dificil, a não ser que a pessoa se sinta muito motivada e que tenha realmente um objetivo maior." (DPL).

No entanto, também reconhecem que o segredo está em percebermos que a crise é, simultaneamente, um momento de reflexão e de oportunidade:

"Se retirarmos o $S$ da palavra 'crise', basta eliminarmos uma letra que ficamos com a palavra 'crie', portanto, porque é que nos havemos de agarrar à crise, como uma coisa terrivel, quando a crise é uma oportunidade de questionar, repensar tudo outra vez (...). Portanto, da crise nascem oportunidades para (...) repensar as coisas, criar e evoluir." (DPL).

Portanto, há que perceber qual o caminho da governação política, qual o rumo que se pretende, antes de implementar um processo de desenvolvimento organizacional, uma vez que, 
uma correta implementação de um plano estratégico está dependente de um processo de mudança, e não basta que se altere a estrutura da organização, é necessário que se considerem quatro variáveis básicas, como o ambiente, a organização, o grupo e o indivíduo.

Só desta forma será possível perceber, de antemão, que trabalhar um processo de mudança organizacional é algo de complexo, significativo, profundo e que exige um correto planeamento, interpretação, conhecimento da cultura da organização, consciência do impacto do processo na organização e congruência entre os objetivos a atingir o desenvolvimento organizacional pretendido.

$9^{\circ}$ indício: o papel da liderança

No que concerne ao papel da liderança, reconhecem que esta "é absolutamente fundamental e decisiva", assegurando que não conhecem "nenhuma estrutura organizacional no mundo que sobreviva quando um líder não é inspirador, quando o líder não é o exemplo, quando o líder não tem a capacidade de estar permanentemente à frente do seu tempo."(DPL).

Destarte, também nas organizações públicas cresce, dia após dia, o conceito de liderança das organizações e a sua enorme importância na definição da estratégia das mesmas.

Para que se possa falar em liderança das organizações, temos de considerar o papel do líder (Denison \& Spreitzer, 1991). Neste sentido, os entrevistados foram mais uma vez consensuais no reconhecimento da importância deste conceito e do impacto que o mesmo tem no sucesso ou insucesso das organizações e das medidas a implementar: "a liderança nas organizações é fundamental, seja em que circunstância for, desde que sejam inspiradoras."; “o papel do líder é muito exigente, mesmo muito, (...) mas é muito importante.” (DPL).

Não obstante os achados deste estudo, reconhecemos algumas limitações, entre elas, podemos citar: a análise micro, realizada em Santo Tirso, tentou observar aspectos políticos, económicos, sociais, tecnológicos, ambientais e legais, mas esses resultados não podem ser generalizados para uma perspectiva macro em Portugal. Apesar de ser um país com uma área geográfica relativamente pequena, existem diferenças acentuadas entre o norte e sul. Não nos esquecendo também das regiões do Alentejo que apresentam características muito específicas. Desta forma, há que se investigar outras autarquias em Portugal para melhor compreensão do fenómeno. Outro ponto a ser mencionado é não termos capturado a oitiva da população de Santo Tirso. Este ponto deve ser objeto de estudos futuros, haja vista a crítica que pode ser desferida 
Machado, J. E. O., Sarmento, J. P., \& Silva, C. A. F. da. (set./dez. 2020). Perceções de lideranças sobre a atuação das autarquias locais no desenvolvimento do desporto em Portugal

em função de focalizarmos apenas a visão da classe dirigente, política e empresarial. Assim, privilegiamos uma visão top-down em detrimento de uma visão bottom-up.

\section{Conclusão}

Este estudo buscou descrever as principais perceções de dirigentes associativos, políticos e empresários sobre a atuação das autarquias locais e dos demais agentes desportivos com quem se relacionam sobre o desenvolvimento do desporto em Portugal. Admitindo-se que o papel das autarquias no desenvolvimento do desporto é sobejamente reconhecido, urge que esta intervenção seja planeada, sustentável e preocupada com o impacto nas gerações futuras, satisfazendo também as necessidades das gerações presentes.

Os vários indícios selecionados nos discursos dos entrevistados apontam para o papel do Estado, das autarquias, das empresas, mas não mencionam o papel das universidades nos projetos de desenvolvimento do desporto. Esta constatação indica um imaginário que não regista a universidade como um ator protagonista. Este achado é crucial neste estudo, tendo em vista que Portugal tem uma das universidades mais antigas do mundo, além do reconhecimento da comunidade internacional no ensino, pesquisa e extensão. Não constatarmos nos discursos dos participantes a presença da universidade como um dos atores fundamentais da hélice do desenvolvimento do desporto, é deveras significativo.

No modelo da hélice tríplice, os clusters de desenvolvimento incluem a participação fundamental das universidades no pleito criativo e de inovação. A perspetiva da sociedade do conhecimento e informação tem nas universidades uma das fontes geradoras de ideias, ações, produtos, processos, enfim, tecnologias que fazem movimentar o processo cumulativo e em espiral do conhecimento.

Cientes desta necessidade, defendemos a realização de planos estratégicos de desenvolvimento desportivo nas autarquias locais, observando os atores da hélice tríplice, dando destaque às parcerias entre autarquias, universidades, empresas e governos.

Para o efeito, há que reconhecer a necessidade de uma melhor governança e de uma liderança capaz de estar à altura das exigências dos tempos de hoje. Liderar é gerir, dirigir e inferir. É antecipar e perspetivar, procurando um justo equilíbrio entre todas as variáveis envolvidas no processo de decisão. 
O planeamento é a função primordial de qualquer organização, sendo a fase do processo de gestão na qual são tomadas decisões sobre os propósitos, as políticas, as estratégias, os programas e os planos que direcionam a organização.

Num mundo em constante evolução, devemos construir estratégias a pensar no futuro, estando atentos aos sinais que o tempo nos dá, para antever e antecipar novos ventos. Um gestor trabalha para ter tempo, caso contrário não faria sentido planear e organizar.

Assim, a questão que se colocará é se o planeamento e a definição de uma estratégia sobrevivem à vontade política, se há coragem na administração pública para definir uma estratégia e não ceder à discricionariedade da atividade na dependência do voto.

\section{Referências}

Amador, V. V. B. (2014). Planeamento estratégico para abertura e implementação de um ginásio desportivo. Porto. Dissertação de Mestrado apresentada ao instituto Superior de Contabilidade e Administração do Porto, Porto.

Almeida, J. F., \& Pinto, J. M. (1986). Da Teoria à Investigação Empírica. Problemas Metodológicos Gerais. In A. S. Silva \& J. M. Pinto (Eds.), Metodologia das Ciências Sociais. Edições Afrontamento, Porto.

Araújo, P. M. (2012). Etnometodologia: consciência, linguagem e o fenómeno da vida cotidiana. Sinais - Revista Eletrónica, Ciências Sociais, 11(1).

Barambão, J. M. P (2012). Plano Estratégico para o Desenvolvimento do Turismo Desportivo no Concelho de Sines, como forma de combater a sazonalidade. (Dissertação de mestrado), ISCTE Business School do Instituto Universitário de Lisboa, Lisboa.

Bardin, L. (2011). Análise de conteúdo. Edições 70, Lisboa.

Bell, J. (1997). Como realizar um projeto de Investigação. Um Guia para Pesquisa em Ciências Sociais e da Educação. Gradiva, Lisboa.

Bento, J. O., \& Constantino, J. M. (2012). Desporto e municípios: políticas, práticas e programas. Visão e Contextos, Lisboa.

Carvalho, M. J. (2007). Os elementos estruturantes do regime jurídico do desporto profissional em Portugal. (Dissertação de Doutorado), Faculdade de Desporto da Universidade do Porto, Porto.

Carvalho, M. J. (1994). Desporto e Autarquias Locais, uma nova via para o desenvolvimento desportivo nacional. Campo das Letras, Porto. 
Machado, J. E. O., Sarmento, J. P., \& Silva, C. A. F. da. (set./dez. 2020). Perceções de lideranças sobre a atuação das autarquias locais no desenvolvimento do desporto em Portugal

Cicourel, A. (1995). Teoria e método em pesquisa de campo. In: Guimarães, A. Z. (org.). Desvendando máscaras sociais. Francisco Alves, Rio de Janeiro.

Chiavenato, I., \& Sapiro, A. (2009). Planeamento estratégico: fundamentos e aplicações. Elsevier, Rio de Janeiro.

da Silva, C. A. F., Terra, B. R. C., \& Votre, S. J. (2008). O modelo da hélice tríplice e o papel da educação física, do esporte e do lazer no desenvolvimento local. Revista Brasileira de Ciências do Esporte, 28(1).

Delgadinho, R. P. L. (2011). Políticas e gestão do desporto municipal- Estudo de caso da empesa municipal Feira Viva, Cultura de Desporto EEM. (Dissertação de mestrado). Universidade do Porto, Porto.

Denison, R. \& Spreitzer G. M. (1991). Organizational culture and organizational developement: a competing values approach. Research in Organizational Change and Development, 5, 1-21.

Etzkowitz, H. (2005). Reconstrução criativa: hélice tríplice e inovação regional. Inteligência Empresarial/Crie/Coppe/UFRJ, n. 23. http://www.epapers.com.br/produtos.asp?codigo_produto=663.

Etzkowitz, H., \& Leydesdorff, L. (1995). The triple helix - university, industry, government relations: a laboratory for knowledge based economic development. In: The triple helix of university, industry, and government relations: the future location of research conference. Amsterdam. http://users.fmg.uva.nl/lleydesdorff/th1/index.htm.

Etzkowitz, H., \& Leydesdorff, L. (2000). The dynamics of innovation: from National Systems and ,,,Mode $2^{\text {ecee }}$ to a Triple Helix of university-industry-government relations. Research Policy, 29, 109-123.http://www.ingentaconnect.com/content/els/00487 333/2000/00000029/00000002/art00055

Etzkowitz, H., \& Zhou, C. (2006). Triple Helix twins: innovation and sustainability. Science and Public Policy, 33(1), 77-83. http://www.ingentaconnect.com/content/beech/spp /2006/00000033/00000001/art00007

Ferrão, A. J. F. (1999). O papel das autarquias no desenvolvimento da actividade física e desportiva dentro e fora da escola do $1^{o}$ ciclo do ensino básico da área educativa de Viseu. (Dissertação de mestrado), Universidade do Porto, Porto.

Garfinkel, H. (2012). Estudos de etnometodologia. Vozes, Petrópolis.

Giacobbo, M. (1997). O desafio da implementação do planejamento estratégico nas organizações públicas. Revista do TCU, 73-107.

Gonçalves, A. (2005). O conceito de governança. XIV Congresso Nacional do COMPEDI. Anais, Fortaleza. http://www.publicadireito.com.br/conpedi/manaus/arquivos/anais/XIVCongresso/078.pdf 
Pires, G. (2005). Gestão de desporto: desenvolvimento organizacional. Apogesd, Porto.

Haguete, T. M. F. (1997). Metodologias qualitativas na Sociologia. Vozes, Petrópolis.

Januário, C., Sarmento, P., \& Carvalho, M. J. (2009). Políticas públicas desportivas: avaliação do nível de execução e eficácia nos Municípios da Área Metropolitana do Porto. Revista Portuguesa de Ciências do Desporto, 9(2), 26-32.

Joaquim, B. A. S. (2009). Desporto e Autarquias locais. Intervenção política na promoção de desporto no concelho de Tondela. Porto. (Estudo monográfico), Universidade do Porto, Porto.

Kreuger, R. A. (1988). Focus groups: A practical guide for applied research. Sage, London.

Kriemadis, T., \& Theakou, E. (2007). Strategic Planning models in public and non profit sport organizations. Sport Management International Journal, 3(2), 27-37. http://iscaweb.org/files/Kriemadis_etal_Strategic_Planning_Models_in_Sport_Organis.pdf

Lobos, J. (1975). Desenvolvimento organizacional: teoria e aplicações. Revista de Administração de Empresas, 15(3), 21-32.

Lundvall, B. (1992). National Systems of Innovation. Pinter, London.

Nelson, R. R. (1993). National Innovation Systems: a Comparative Analysis. Oxford Univ. Press, New York.

Oliveira, L. R. (2012). Sustentabilidade: da evolução dos conceitos à implementação como estratégia nas organizações. Produção, 22(1), 70-82.

Paipe, G. (2016). Políticas públicas desportivas: estudo centrado em municípios de Moçambique. (Dissertação de Doutorado), Universidade do Porto, Porto.

Paz, F. J., \& Kipper, L. M. (2016). Sustentabilidade nas organizações: vantagens e desafios. GEPROS. Gestão da Produção, Operações e Sistemas, 11(2), 85-102.

Pires, G. (2005). Gestão de desporto: desenvolvimento organizacional. Apogesd, Porto.

Pizarro, J. A. (2017). Governança desportiva: uma inflexão da governança global. Revista de Relaciones Internacionales, Estrategia y Seguridad, 13(1), 195-219.

Sábato, J., \& Mackenzie, M. (1982). La Producción de Tecnología. Autónoma o Transnacional. Nueva Imagen, México.

Sancho, J. A. M. (2004). Planificación Desportiva - Teoria y Prática. INDE, Barcelona. Sarmento, J. P, Pinto, A., Costa, C. P., \& Silva, C. A. F (2011). O evento desportivo como fator de desenvolvimento. Revista Intercontinental de Gestão Desportiva, 1(1), 1-14. 
Machado, J. E. O., Sarmento, J. P., \& Silva, C. A. F. da. (set./dez. 2020). Perceções de lideranças sobre a atuação das autarquias locais no desenvolvimento do desporto em Portugal

Silva, C. A. F. et al. (2015). A contribuição da etnometodologia para os estudos sociológicos na educação física brasileira. Revista Movimento, 21(1), 217-232.

Silva, C. A. F., \& Votre, S. J. (2012). Etnometodologias. Rio de Janeiro: Comunicação Editora.

Silva, E. A. (2013). As metodologias qualitativas de investigação nas Ciências Sociais. Revista Angolana de Sociologia, 12, 77-99.

Silva, C. A. F., Lopes, J. P. S. R., \& Araújo Netto, J. (2010). Educação física, desenvolvimento e inovação: o argumento da hélice tríplice. Motriz, 16(4), 9951005. https://doi.org/10.5016/1980-6574.2010v16n4p995

Soares, B. A. (2009). Intervenção política na promoção de desporto e actividade física no concelho de Tondela. Porto. (Estudo monográfico), Faculdade de Desporto da Universidade do Porto, Porto.

Soares, A. V. (2006). A gestão por competências e o triple bottom line como padrões para o alcance da sustentabilidade empresarial. III CNEG, Niterói, RJ, Brasil. https://www.inovarse.org/artigos-por-edicoes/III-CNEG-2006/321.pdf

Steigleder, M. L., Santos, R. F., \& da Silva, C. A. F. (2020). Sport as a vehicle for socioeducational transformation: a study of the Fernanda Keller Project. Motriz: Revista de Educação Física, 26(1), e10200086. https://dx.doi.org/10.1590/s1980-6574202000010086

Teixeira, S. (2011). Gestão Estratégica. Lisboa: Escolar Editora.

Terence, A. C. F. (2002). Planejamento estratégico como ferramenta de competitividade na pequena empresa. (Dissertação de Mestrado), Escola de Engenharia de São Paulo da Universidade de São Paulo, São Paulo.

Venturini, L., \& Lopes., L. (2015). O modelo Triple Bottom Line e a sustentabilidade na administração pública: pequenas práticas que fazem a diferença. (Monografia de Especialização), Universidade Federal de Santa Maria, Santa Catarina. http://repositorio.ufsm.br/handle/1/11691. 